\title{
DOSSIER
}

Complicações da Diabetes

\section{Complicações renais da diabetes mellitus}

\author{
CLÁUdIA FREITAS ANTÃO*, ROSA GALLEGO**, JORGE CALDEIRA***
}

\section{RESUMO}

Introdução: A nefropatia diabética afecta cerca de 10 a $40 \%$ dos doentes diabéticos e é hoje a patologia mais frequentemente associada a novos casos de doentes hemodialisados. Com o aumento da prevalência da diabetes mellitus a nível mundial, aliado à maior sobrevida dos doentes diabéticos, é de esperar que a prevalência das complicações associadas a esta epidemia também venha a aumentar. Esta realidade assume uma maior gravidade pela evidência da relação entre a nefropatia diabética e o aumento do risco de morbilidade e mortalidade cardiovasculares nestes doentes, tornando essencial o conhecimento das medidas diagnósticas, preventivas e terapêuticas necessárias para uma correcta abordagem e melhoria dos cuidados prestados.

Objectivo: Realizar uma revisão, assente na Medicina Baseada na Evidência, dos conceitos, factores de risco e principais medidas preventivas, diagnósticas e terapêuticas envolvidas na nefrqpatia diabética.

Mefodologia: Foi realizada uma pesquisa documental nas bases de dados da Med Line, Pubmed Central, TRIP Database, Bandolier, National Guideline Clearinghouse $e$ Index RMP online, que resultou na selecção de 104 artigos. Foram também consultadas fontes bibliográficas de referência. Conclusão: A nefropatia diabética cursa com albuminúria, hipertensão e o declínio da taxa de filtração glomerular. A prevenção e tratamento passam pelo controlo apertado dos seus principais factores de risco: hiperglicemia e hipertensão. 0 início da terapêutica com inibidores da enzima de conversão da angiotensina ou antagonistas dos receptores da angiotensina, mesmo antes do aparecimento da microalbuminúria, é fundamental para a não progressão da lesão renal e diminuicão da morbimortalidade cardiovascular associada. Outras medidas terapêuticas, como o controlo do perfil lipídico, dieta, exercicio físico, perda ponderal e cessação tabágica, para além de modularem o risco cardiovascular, também poderão contribuir para a nefrqurotecção.

Palavras-Chave: Diabetes Mellitus; Complicações da Diabetes Mellitus; Nefropatia; Microalbuminúria; Macroalbuminúria; Risco Cardiovascular.
*Interna do Internato Complementar de Medicina Geral e Familiar. Centro de Saúde da Póvoa de Santa Iria Unidade de Saúde de Vialonga **Médica de Família. Centro Saúde de Vila Franca Xira ${ }^{* * *}$ Chefe de Serviço de Diabetologia. Hospital Santa Maria

\section{INTRODUCÃ̃o}

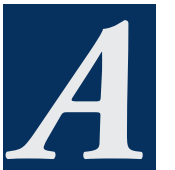

nefropatia diabética, caracterizada por albuminúria, hipertensão arterial (HTA) e declínio progressivo da função renal, afecta cerca de dez a 40\% dos doentes com diabetes mellitus (DM) ${ }^{1} \mathrm{e}$ constitui a principal causa de insuficiência renal terminal em doentes que iniciam hemodiálise de nuovo. ${ }^{2}$

Estudos comprovam que a nefropatia diabética é um factor de risco de morbilidade e mortalidade por doença cardiovascular em doentes diabéticos, sobretudo se à proteinúria estiver asso- ciada HTA. ${ }^{3-6}$

Com o aumento da prevalência da DM a nivel mundial e a cada vez maior sobrevida dos doentes diabéticos, é de esperar um aumento da prevalência das suas complicações. ${ }^{1}$ Programas de prevenção e controlo são essenciais e a adopção de medidas de diagnóstico e intervenção precoce é crítica para a diminuição da progressão da insuficiência renal nestes doentes.

A implementação destas medidas está em curso há vários anos, o que estará provavelmente na base da diminuição da taxa de incidência da progressão da micro para macroalbuminúria na nefropatia diabética; ${ }^{7}$ no entanto, estudos demonstram que estas medidas se encontram longe de atingir os objectivos pretendidos. ${ }^{8}$

Desta forma, é fundamental que os médicos estejam familiarizados com as estratégias preventivas e terapêuticas recomendadas e que as concretizem na sua prática clínica, de forma a melhorar a qualidade da prestação dos cuidados de saúde a este grupo de risco.

Este artigo tem como objectivo fazer uma revisão baseada na evidência dos conceitos, factores de risco e principais medidas preventivas, diagnósticas e terapêuticas promotoras da nefroprotecção na DM.

\section{Metodologia}

Com recurso às bases de dados Medline, Pubmed Central, TRIP Database, Bandolier, National Guideline Clearinghouse e Index RMP online foi realizada uma pesquisa de artigos de revisão, 


\section{DOSSIER}

meta-análises e ensaios clínicos aleatorizados, publicados entre Janeiro de 1990 e Abril de 2007, utilizando os seguintes termos de pesquisa, isoladamente ou em combinação: «Nefropatia Diabética", "Diabetes Mellitus", "Complicações da Diabetes Mellitus", "Microalbuminúria", "Macroalbuminúria" e "Proteinúria" (Diabetic Nephropathy, Diabetes Mellitus, Diabetes Mellitus Complications, Microalbuminuria, Macroalbuminuria, Proteinuria). Também foram analisados os "related articles" decorrentes das pesquisas.

Seleccionaram-se os artigos cujo título e resumo foram considerados relevantes para a revisão do tema em questão, tendo sido incluídos um total de 104 artigos.

A pesquisa documental passou ainda pela consulta de obras de referência.

\section{Definicão, ClínICa e História Natural}

A nefropatia diabética é um síndrome clínico caracterizado pela presença de proteinúria (Quadro I) e/ou alterações da função renal [creatinina sérica, clearance da creatinina e taxa de filtração glomerular (TFG)], determinadas em pelo menos duas ocasiões diferentes, separadas por 3-6 meses de intervalo. ${ }^{9}$ A probabilidade das alterações da função renal serem consequência da DM é maior em doentes que apresentam retinopatia diabética. ${ }^{9} \mathrm{Em}$ termos clínicos, a nefropatia diabética é acompanhada pelo aumento progressivo da proteinúria, HTA, dislipidemia, diminuição da TFG e aumento do risco de morbilidade e mortalidade cardiovasculares. ${ }^{10-17}$

Doentes com microalbuminúria apresentam um risco mais elevado de progressão para macroalbuminúria $\mathrm{e}$ insuficiência renal crónica (IRC), ${ }^{18-20}$ sendo o declínio da função renal semelhante nos doentes diabéticos tipo $1 \mathrm{e}$ tipo 2. No entanto, a história natural da nefropatia diabética encontra-se melhor definida na diabetes tipo $1,{ }^{21,22}$ podendo ser dividida em cinco fases (Quadro II). Na diabetes tipo 2 o curso da doença é mais variável devido à dificuldade na determinação da data exacta do início da diabetes e também à existência de co-morbilidades que contribuem para a doença renal..$^{23}$ Por esse motivo, em doentes diabéticos tipo 2 devem ser excluídas, primeiramente, outras causas de patologia renal (Quadro III).

Existem, ainda, outras diferenças entre a nefropatia diabética na diabetes mellitus tipo 1 e tipo 2 . Na diabetes tipo 2 é mais frequente a albuminúria estar presente à data do diagnóstico. A presença concomitante de HTA, também mais frequente em doentes diabéticos tipo 2 e responsável pelo desenvolvimento de insuficiência renal, pode conduzir a uma evolução mais rápida da nefropatia. Finalmente, a microalbuminúria é um factor de prognóstico mais fiável na diabetes tipo 1 comparativamente com a diabetes tipo $2 .{ }^{24}$

QUADRO I

\begin{tabular}{|c|c|c|c|}
\hline \multicolumn{4}{|c|}{ MÉTODOS DE MEDIC̣̃̃O E VALORES DE REFERÊNCIA DA EXCREÇ̃̃ DE ALBUMINA9 } \\
\hline Método & Normoalbuminúria & Microalbuminúria & $\begin{array}{c}\text { Macroalbuminúria/ } \\
\text { Proteinúria }\end{array}$ \\
\hline Colheita de Urina 24H & $<30 \mathrm{mg} / 24 \mathrm{~h}$ & $30-300 \mathrm{mg} / 24 \mathrm{~h}$ & $>300 \mathrm{mg} / 24 \mathrm{~h}$ \\
\hline Amostra ocasional (spot urine sample) & $\leq 20 \mathrm{mg} / \mathrm{L}$ & $>20 \mathrm{mg} / \mathrm{L}$ & $>200 \mathrm{mg} / \mathrm{L}$ \\
\hline Razão albumina/creatinina & $\begin{array}{l}q<2,5 \mathrm{mg} / \mathrm{mmol} \\
o<3,5 \mathrm{mg} / \mathrm{mmol}\end{array}$ & $\begin{array}{l}q \geq 2,5 \mathrm{mg} / \mathrm{mmol} \\
\sigma^{\prime} \geq 3,5 \mathrm{mg} / \mathrm{mmol}\end{array}$ & $\geq 30 \mathrm{mg} / \mathrm{mmol}$ \\
\hline
\end{tabular}




\section{QUADRO II}

\begin{tabular}{|c|c|c|c|c|c|c|c|}
\hline \multicolumn{8}{|c|}{ FASES DA PROGRESSÃO DA NEFROPATIA NA DIABETES TIPO 1} \\
\hline Fases & Início & Clínica & TFG* & $\begin{array}{l}\text { Albuminúria } \\
\text { (mg/24h) }\end{array}$ & TA† & Histologia & Prognóstico \\
\hline Fase 1 & $\begin{array}{l}\text { À data do } \\
\text { diagnóstico }\end{array}$ & Assintomática & $\uparrow \uparrow$ & Normal & Normal & $\begin{array}{l}\text { Espessamento } \\
\text { da MBG‡ e mesângio }\end{array}$ & \\
\hline Fase 2 & $\begin{array}{l}<10 \text { anos após } \\
0 \text { diagnóstico }\end{array}$ & Assintomática & $\uparrow /$ Normal & Normal & Normal & $\begin{array}{l}\text { Hipertrofia celular dos glomérulos } \\
\text { e túbulos; Espessamento da MBG } \\
\text { e tubular }\end{array}$ & $\begin{array}{l}\text { Cerca de } 33 \% \text { dos doentes } \\
\text { evolui para a fase } 3\end{array}$ \\
\hline Fase 3 & $\begin{array}{l}\geq 10 \text { anos após } \\
0 \text { diagnóstico }\end{array}$ & Microalbuminúria & Normal & $30-300$ & Normal & Glomerulosclerose nodular & $\begin{array}{l}30-45 \% \text { dos doentes } \\
\text { evolui para a fase } 4\end{array}$ \\
\hline Fase 4 & $\begin{array}{l}15-20 \text { anos após } \\
\text { o diagnóstico }\end{array}$ & $\begin{array}{l}\text { Macroalbuminúria } \\
\text { HTA } \\
\text { Edemas }\end{array}$ & Normal/ $\downarrow$ & $>300$ & Normal $/ \uparrow$ & $\begin{array}{l}\text { Glomerulosclerose nodular } \\
\text { e difusa; Áreas de fibrose renal }\end{array}$ & $\begin{array}{l}50 \% \text { dos doentes evolui } \\
\text { para a fase } 5\end{array}$ \\
\hline Fase 5 & $\begin{array}{l} \pm 7 \text { anos após início } \\
\text { de proteinúria } \\
\text { persistente }\end{array}$ & $\begin{array}{l}\text { IRC } \\
\text { Síndrome nefrótico }\end{array}$ & $\downarrow \downarrow$ & $>300$ & $\uparrow \uparrow$ & Fibrose renal & Hemodiálise/Transplante \\
\hline
\end{tabular}

* Taxa de filtração glomerular; † Tensão arterial; ‡ Membrana basal glomerular; ¥ Insuficiência renal crónica

A nefropatia diabética surge em apenas $40 \%$ dos doentes diabéticos, mesmo com níveis de glicemia elevados e mantidos por relativamente longos períodos, o que leva a crer que apenas uma percentagem de doentes é susceptível de desenvolver a patologia renal. Estudos comprovam que a predisponibilidade genética contribui para o aparecimento de nefropatia diabética, tanto na diabetes tipo 1 como na diabetes tipo 2. ${ }^{25-28}$ Outros factores de risco (Guadro IV), que contribuem para a progressão da nefropatia, são a duração da diabetes, a idade, sexo masculino, tabagismo, hipertensão arterial, hiperglicemia e dislipidemia. ${ }^{29-34}$ Também alguns grupos étnicos (afro-americanos, africanos e indianos) apresentam maior risco de progredirem para IRC terminal. $2,23,35-37$

A intervenção sobre factores de risco modificáveis como a HTA, hiperglicemia e dislipidemia tem sido responsável pela diminuição da taxa de progressão de micro para macroalbuminúria verificada em doentes diabéti$\cos ^{38}$

\section{EPIDEMIOLOGIA}

A incidência de nefropatia diabética está a aumentar, por um lado devido ao número crescente de casos de diabetes tipo 2 e por outro pela maior esperança de vida destes doentes, graças às medidas de intervenção adoptadas..$^{39}$ Em 1997, a prevalência global de nefropatia diabética era de cerca de 124 milhões e espera-se que no ano 2010 atinja os 221 milhões de doentes. ${ }^{1}$

Em doentes com diabetes tipo 1 a incidência de microalbuminúria está estimada em 12,6\% em 7,3 anos e uma $^{40}$ prevalência de aproximadamente 33\% ao fim de 18 anos..$^{41}$ Em diabéticos tipo 2 estima-se uma incidência de $2 \%$ por ano e uma prevalência de $25 \%$ ao fim de dez anos. ${ }^{42}$

A prevalência de proteinúria em diabéticos tipo 1 varia entre 15 a $40 \%$ e atinge o seu pico de incidência cerca de 15 a 20 anos após o diagnóstico da diabetes. ${ }^{43,44}$ Em doentes com diabetes tipo 2 a prevalência varia entre os cinco e os $20 \% .{ }^{42,45}$ 


\begin{tabular}{|c|c|}
\hline \multicolumn{2}{|c|}{ QUADRO III } \\
\hline $\begin{array}{r}\text { DIAGNÓSTICO DIFERE } \\
\text { DIABÉTICA }\end{array}$ & $\begin{array}{l}\text { NCIAL DA NEFROPATIA } \\
\text { A DM TIPO } 2\end{array}$ \\
\hline $\begin{array}{l}\text { - Litíase Renal } \\
\text { - Obstrução do Tracto } \\
\text { Urinário } \\
\text { - Infecção Urinária } \\
\text { - Glomerulonefrite } \\
\text { - Patologia Renal } \\
\text { associada a Infecção HIV, } \\
\text { Hepatite B ou C } \\
\text { - HTA Renovascular }\end{array}$ & $\begin{array}{l}\text { - Estenose da Artéria Renal } \\
\text { - Trombose da Veia Renal } \\
\text { - Lúpus Eritematoso } \\
\text { Sistémico } \\
\text { - Crioglobulinemia } \\
\text { - Mieloma Múltiplo } \\
\text { - Amiloidose } \\
\text { - Outras Glomerulopatias }\end{array}$ \\
\hline
\end{tabular}

\begin{tabular}{|c|c|}
\hline \multicolumn{2}{|c|}{ QUADRO IV } \\
\hline $\begin{array}{l}\text { FACTORES DE RISC } \\
\text { DA NEFROPA }\end{array}$ & $\begin{array}{l}\text { O DA PROGRESSÃO } \\
\text { TIA DIABÉTICA }\end{array}$ \\
\hline $\begin{array}{l}\text { - Idade } \\
\text { - Sexo } \\
\text { - Raça } \\
\text { - Etnia } \\
\text { - Susceptibilidade Genética } \\
\text { - Hiperglicemia } \\
\text { - HTA }\end{array}$ & $\begin{array}{l}\text { - Presença de Retinopatia } \\
\text { Diabética } \\
\text { - Tabagismo } \\
\text { - Dislipidemia } \\
\text { - Obesidade } \\
\text { - Tempo de evolução } \\
\text { da DM } \\
\text { - Dieta com alto teor } \\
\text { proteico }\end{array}$ \\
\hline
\end{tabular}

Ao fim de 20 anos de diabetes diagnosticada o risco cumulativo de proteinúria é de $27 \%$ na diabetes tipo 2 e de $28 \%$ na diabetes tipo $1 .{ }^{46}$

\section{PatofisIOLOGIA}

A diabetes provoca alterações estruturais características na histologia renal. As mais precoces ocorrem ao nível do glomérulo e caracterizam-se pelo espessamento da membrana basal glomerular e do mesângio, devido à acumulação de matriz extracelular, o que conduz ao aumento inicial do volume renal, contrariamente a outras formas de patologia renal crónica em que o volume renal se encontra diminuído (excepto na amiloidose e na doença do rim poliquístico). ${ }^{47}$

As causas exactas da nefropatia diabética são ainda desconhecidas; no entanto, estudos sugerem que alguns dos mecanismos envolvidos incluam a hiperglicemia, a presença em circulação de complexos glicosilados e a activação de biomarcadores inflamatórios. ${ }^{47}$

A hiperglicemia é responsável pela hiperfiltração renal que por sua vez induz o aumento da pressão capilar glomerular. Esta promove a proliferação celular regulada pela libertação do factor de crescimento TGF- $\alpha$ que vai mediar a hipertrofia e divisão celular e mais tarde o processo de fibrose renal, através da estimulação da produção de colagénio e fibronectina. Os produtos glicosilados, resultantes da ligação da glicose a proteínas no rim, também contribuem para a lesão renal, através da estimulação de factores promotores de fibrose. ${ }^{47}$

A glomerulosclerose na diabetes é caracterizada pelo espessamento da membrana basal glomerular, esclerose mesangial difusa e nodular (nódulos de Kimmelstiel-Wilson), arteriosclerose hialina, microaneurismas e também alterações a nível tubular e intersticial. ${ }^{47-49}$ As alterações estruturais são mais heterogéneas em doentes diabéticos tipo 2 , com micro ou macroalbuminúria, que nos doentes diabéticos tipo $1 .{ }^{22,34,50}$

A gravidade das lesões renais correlaciona-se com a taxa de filtração glomerular, grau de albuminúria, duração da diabetes, grau de controlo da glicemia e factores genéticos. ${ }^{49-51}$ Não é, no entanto, possível identificar lesões glomerulares patognomónicas das fases de normoalbuminúria, microalbuminúria e proteinúria nos doentes diabéticos tipo 1 e 2 com nefropatia. ${ }^{51-53}$

\section{DIAGNóstico e RASTREIO}

O diagnóstico da nefropatia diabética 


\begin{tabular}{|c|c|}
\hline \multicolumn{2}{|c|}{ AVALIAC̣ÃO DO DOENTE COM PROTEINÚRIA } \\
\hline $\begin{array}{l}\text { História } \\
\text { - Diabetes Mellitus } \\
\text { - Espuma na urina } \\
\text { - Proteinúria de outra forma não explicada num } \\
\text { doente com diabetes } \\
\text { - Retinopatia Diabética } \\
\text { - Astenia e edemas dos membros inferiores secundários } \\
\text { à hipoalbuminemia (síndroma nefrótico) } \\
\text { - Patologia cardiovascular associada (HTA, doença arterial } \\
\text { periférica, doença coronária,...) }\end{array}$ & $\begin{array}{l}\text { Exame Objectivo } \\
\text { - HTA } \\
\text { - Evidência de Retinopatia observada por fundoscopia ou } \\
\text { angiografia com fluoresceina } \\
\text { - Doença vascular periférica (pulsos periféricos pouco } \\
\text { amplos, sopros vasculares) } \\
\text { - Evidência de Neuropatia (alterações da sensibilidade } \\
\text { fina, diminuição ROT*) } \\
\text { - S4 à auscultação cardíaca } \\
\text { - Úlceras venosas }\end{array}$ \\
\hline $\begin{array}{l}\text { Laboratório } \\
\text { - Rastreio Microalbuminúria } \\
\text { - Creatinina sérica } \\
\text { - Ionograma } \\
\text { - Cálculo TFG† } \\
\text { - Urina II com análise do sedimento urinário }\end{array}$ & $\begin{array}{l}\text { Imagiologia } \\
\text { - Ecografia renal } \\
\text { Outros Procedimentos } ¥ \\
\text { - Electroforese proteínas séricas e urinárias } \\
\text { - Biópsia renal }\end{array}$ \\
\hline
\end{tabular}

* Reflexos Osteotendinosos; † Taxa de Filtracão Glomerular; † Exames complementares de diagnóstico não recomendados como rotina, apenas indicados perante dificuldades no diagnóstico;

depende da detecção e monitorização da presença de proteínas na urina, com recurso a exames laboratoriais que podem incluir radioimunoensaios, imunoturbidimetria ou "enzime-linked immunossorbent assay" (ELISA). Estes vários testes variam quanto à sua natureza e não é claro qual o método mais eficaz. ${ }^{54-56}$

No entanto, é necessário ter em conta a variação diária da excreção de albumina urinária e que perante um resultado alterado, a sua confirmação deve ser realizada em duas de três amostras recolhidas num periodo de 3-6 meses. ${ }^{57}$

Uma vez confirmada a micro ou macroalbuminúria o doente deve ser submetido a uma investigação meticulosa, a fim de excluir outras possiveis etiologias responsáveis pela lesão renal (Guadro III). O diagnóstico diferencial deve basear-se na história clínica, exame objectivo e exames laboratoriais e imagiológicos (Guadro V).

Em doentes com diabetes tipo 1 o diagnóstico de nefropatia diabética é mais facilmente estabelecido quando perante uma DM com um curso superior a dez anos e/ou na presença de retinopatia diabética. Também em doentes diabéticos tipo 2 o diagnóstico de nefropatia diabética é mais provável quando associado a retinopatia ou neuropatia diabéticas. ${ }^{58,59}$ Todavia, a ausência de lesões de órgãos-alvo não exclui o diagnóstico.

Estudos confirmam que a retinopatia diabética é um factor predictor do desenvolvimento de nefropatia em doentes diabéticos tipo 2 , pelo que o seu rastreio deve ser realizado com regularidade nestes doentes. ${ }^{19,60} \mathrm{Ou}-$ tras complicações da diabetes, como a neuropatia, também devem ser despistadas, uma vez que surgem com maior frequência associadas à lesão renal. ${ }^{27,60}$

Dado que os doentes diabéticos com nefropatia apresentam, também, um maior risco cardiovascular ${ }^{3-5}$ devem, 
TFG $=170 \times\left[\mathrm{P}_{\mathrm{c}}\right]^{-0,858} \times[\text { idade }]^{-0,167} \times(0,822$ se sexo $q) \times(1,180$ se raça negra $) \times[\mathrm{BUN}]^{-0,170} \times[\text { Alb }]^{+0,318}$

$\mathrm{Pcr}=$ creatinina sérica $(\mathrm{mg} / \mathrm{dL}) ;$ Idade em anos; BUN = ureia plasmática $(\mathrm{mg} / \mathrm{dL}) ; A \mathrm{lb}=$ albumina sérica $(\mathrm{g} / \mathrm{dL}) ;$

igualmente, ser pesquisadas a presença de doença coronária e outras complicações da doença arterioesclerótica, como doença arterial periférica ou estenose carotídea ou da artéria renal. ${ }^{7}$

Relativamente ao recurso à biópsia renal para o diagnóstico etiológico da lesão renal, os critérios não se encontram bem definidos. Na diabetes tipo 1, parâmetros como o quadro de síndrome nefrótico agudo, valores de proteinúria rapidamente ascendentes e declínio da taxa de filtração glomerular têm sido utilizados como indicadores para a realização de biópsia renal, especialmente na presença de diabetes de curta duração ou na ausência de retinopatia diabética. ${ }^{61} \mathrm{Em}$ doentes diabéticos tipo 2 os critérios são menos claros, já que a lesão renal de causa não diabética é mais frequente e os beneficios da identificação e tratamento destas lesões nestes doentes não foram, ainda, estabelecidos. $^{7}$

O rastreio da nefropatia diabética ( $\mathrm{Fi}$ gura 1) deve ser iniciado na altura do diagnóstico em doentes com diabetes tipo 2 e cerca de cinco anos após o diagnóstico em doentes diabéticos tipo 1, devendo ser depois repetido anualmente em ambos os grupos de doentes. ${ }^{23} \mathrm{Na}$ diabetes tipo 1 o rastreio deve ser iniciado mais precocemente, 1 ano após o diagnóstico, quando perante um doente com um mau controlo metabólico ou após o início da puberdade. ${ }^{23}$

O rastreio não deve ser realizado na presença de outras patologias que cursam com proteinúria, como infecções urinárias, hematúria, sindrome febril, HTA não controlada ou insuficiência cardíaca congestiva. ${ }^{62,63}$

\section{Monitorização da Função Renal}

O doseamento da excreção urinária de albumina é a pedra angular do diagnóstico da nefropatia diabética. No entanto, a TFG é o parâmetro mais fiável para a monitorização da função renal e deve ser calculada nos doentes diabéticos com micro e macroalbuminúria. ${ }^{64}$

A TFG pode ser determinada com o auxílio de técnicas específicas (clearance da inulina, ${ }^{15} \mathrm{Cr}$-EDTA, ${ }^{125}$ I-iotalamato). ${ }^{65,66}$ Pode também ser calculada com o auxilio de equações que têm em conta a clearance da creatinina, sexo, idade, raça e peso do doente. ${ }^{66}$ No Quadro VI está representada a equação recomendada pela National Kidney Foundation, por melhor se correlacionar com o valor real da TFG (um calculador virtual pode ser utilizado no website da fundação em http://www.kidney.org). Os valores de referência da TFG em indivíduos jovens variam entre $80 \mathrm{e}$ $130 \mathrm{ml} / \mathrm{minuto} / 1,73 \mathrm{~m}^{2}$, diminuindo cerca de $10 \mathrm{ml} / \mathrm{minuto} /$ década após os 50 anos de idade. ${ }^{63}$

Diminuições na TFG podem ser encontradas em doentes diabéticos tipo 1 e tipo 2 com normoalbuminúria, o que significa que esta última não constitui um factor de protecção da lesão renal, pelo que, para além da excreção urinária de albumina, deve ser determinado, com regularidade, o valor da $\mathrm{TFG}$, para a monitorização adequada da função renal. ${ }^{66,67}$

A velocidade de declínio da função renal correlaciona-se com a gravidade da lesão renal e o nível de controlo metabólico. ${ }^{10}$ 


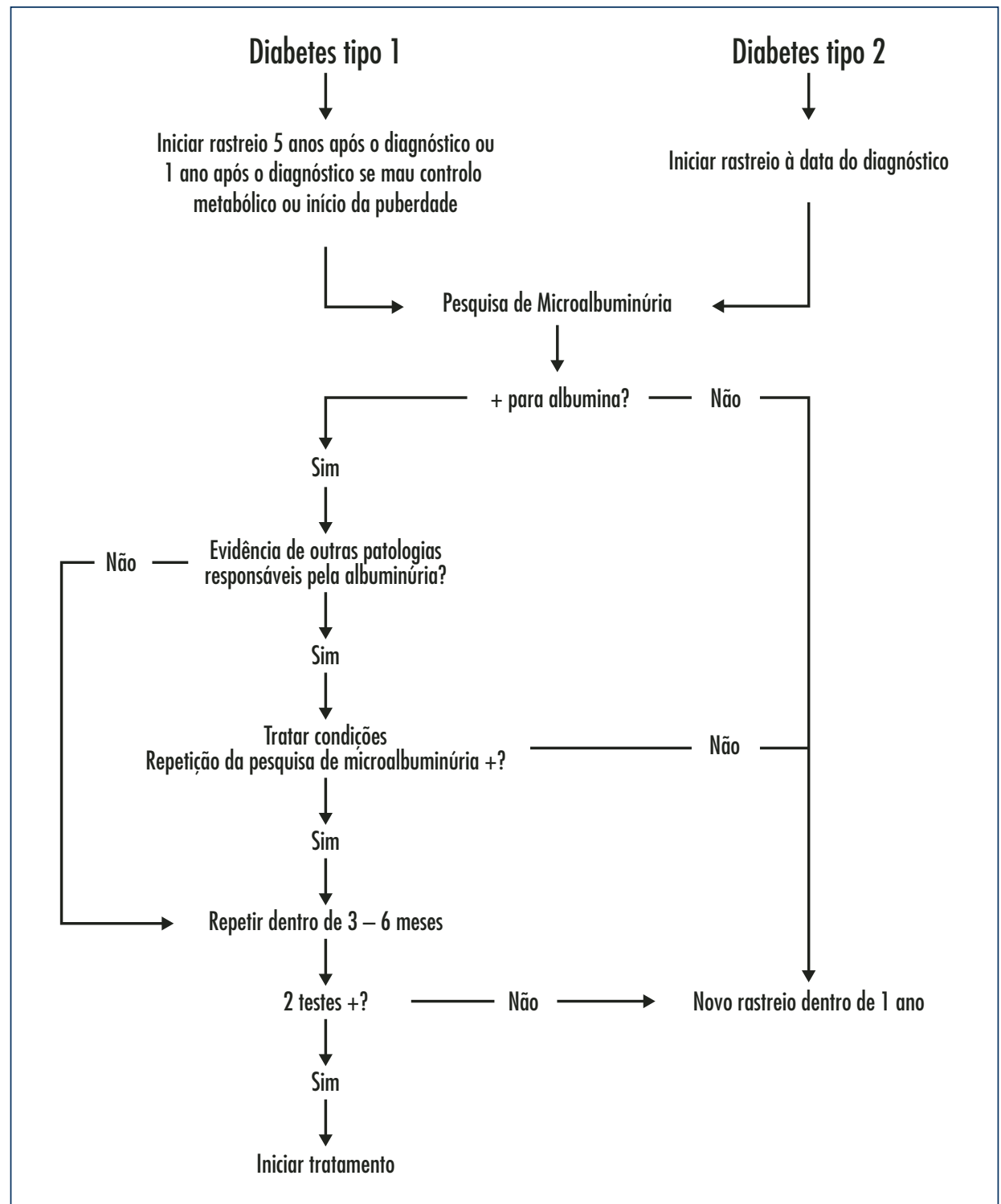

Figura 1. Algoritmo de Rastreio da Nefropatia Diabética.

Em doentes diabéticos tipo 1 com proteinúria estima-se que, sem qualquer intervenção terapêutica, a TFG diminua a um ritmo de cerca de $1,2 \mathrm{ml} / \mathrm{minu}$ to/mês. ${ }^{7}$ Em diabéticos do tipo 2 o ritmo de diminuição é mais variável, numa média de cerca de $0,5 \mathrm{ml} /$ minuto/mês. $^{7}$

A referenciação para um nefrologista deve ser feita quando a TFG atinge o valor de $30 \mathrm{ml} /$ minuto $/ 1,73 \mathrm{~m}^{2}$, para avaliação e decisão terapêutica. ${ }^{64}$

\section{Prevenção}

As intervenções destinadas a prevenir as complicações renais da diabetes incidem no tratamento dos seus factores de risco.

\section{Controlo da Tensão Arterial}

Estudos demonstram que tanto a nefropatia diabética como a HTA estão as- 
sociadas a um aumento da mortalidade por doença cardiovascular. ${ }^{3}$

Estima-se que a prevalência da HTA seja de cerca de $40 \%$ em doentes diabéticos tipo 1 e cerca de $70 \%$ em diabéticos tipo $2 .^{7}$

Um controlo rigoroso da HTA está associado à redução do risco de doença cardiovascular e eventos microvasculares adversos (retinopatia, hemorragia do vítreo, IRC) em doentes com diabetes, bem como à diminuição, em cerca de $20 \%$, do risco de desenvolver microalbuminúria. ${ }^{68}$

Os inibidores da enzima de conversão da angiotensina (IECA's) e os antagonistas dos receptores da angiotensina (ARA's) são os fármacos de eleição no tratamento da HTA em doentes diabéticos, pelo seu efeito nefroprotector. ${ }^{69,70}$

A sua acção na prevenção da nefropatia na DM tipo 1 não está ainda bem estabelecida, embora a administração de perindopril a diabéticos tipo 1 normotensos e com normoalbuminúria, por um período de três anos, tenha sido eficaz no atraso da progressão da microalbuminúria. ${ }^{71}$

Em doentes diabéticos tipo 2, estudos apontam no sentido destas classes de fármacos terem efeitos renoprotectores e cardioprotectores. ${ }^{72,73}$

Nos doentes diabéticos recomendam-se valores tensionais inferiores a $130 /$ /80 mmHg. ${ }^{74}$

\section{Controlo da Glicemia}

Ensaios clínicos demonstraram que níveis de $\mathrm{HbAlc}<7,0 \%$ estão associados à diminuição do risco de nefropatia diabética em doentes diabéticos tipo $1 \mathrm{e}$ tipo $2 .{ }^{75,76} \mathrm{O}$ tratamento intensivo da hiperglicemia reduziu em $30-40 \%$ o risco de desenvolvimento de microalbuminúria. 75,76

Estes resultados são indicativos da necessidade de um controlo rigoroso da glicemia, com o objectivo de atingir valores de $\mathrm{HbAlc}<7,0 \%$, de forma a pre- venir as lesões renais e o desenvolvimento de microalbuminúria.

\section{Restrição Proteica}

Não foram encontrados estudos relativos aos efeitos da restrição proteica na dieta na prevenção da nefropatia diabética.

\section{Perfil Lipídico}

Não foram encontradas evidências conclusivas do efeito das estatinas na prevenção do declínio da função renal. ${ }^{77}$

No entanto, estes fármacos podem estar indicados em doentes diabéticos a fim de reduzirem o risco de morbilidade e mortalidade cardiovasculares neste grupo vulnerável. ${ }^{78}$

\section{Nefrotoxinas}

O contacto com nefrotoxinas é um factor de risco potencialmente modificável e que pode prevenir e/ou retardar o aparecimento da lesão renal.

O tabagismo tem sido apontado como um factor que contribui para o aparecimento e progressão da nefropatia diabética. ${ }^{30,79}$

Drogas responsáveis por insuficiência renal, como anti-inflamatórios não esteróides, ${ }^{80}$ devem ser evitadas nestes doentes. No entanto, a terapêutica preventiva de eventos cardiovasculares com ácido acetilsalicílico (AAS) em baixa dose (100-150 mg/dia) provou não ter impacto negativo na função renal de doentes diabéticos tipo 1 e tipo 2 com micro ou macroalbuminúria. ${ }^{81} \mathrm{~A}$ terapêutica com este antiagregante, na dose de $75-162 \mathrm{mg} /$ dia, está recomendada para prevenção primária e secundária em todos os doentes diabéticos com idades superiores a 40 anos e/ou com patologia cardiovascular associada. ${ }^{82}$

A utilização de agentes de radiocontraste, como os utilizados na angiografia, podem ser responsáveis por insuficiência renal aguda em diabéticos com patologia renal ${ }^{83}$ e não devem ser utilizados nestes doentes. 


\section{TERAPÊUTICA}

Os princípios terapêuticos utilizados no tratamento da nefropatia diabética seguem os mesmos critérios que as estratégias preventivas.

Os objectivos terapêuticos e as estratégias de intervenção encontram-se sistematizados na Figura 2 e visam a prevenção da progressão da microalbuminúria para macroalbuminúria, com consequente beneficio para a função renal. Medidas de redução do risco de morbilidade e mortalidade por eventos cardiovasculares devem também ser ponderadas.

\section{Controlo da Tensão Arterial}

Vários estudos demonstraram que o tratamento da HTA em doentes diabéticos do tipo 1 e do tipo 2 com microalbuminúria tem efeitos positivos sobre a excreção de albumina pelo rim. ${ }^{69,84,85}$

Os objectivos da terapêutica antihipertensora são atingir um valor tensional inferior a 130/80 mmHg em doentes diabéticos, no geral,$^{74}$ ou $125 / 75 \mathrm{mmHg}$ em doentes com proteinúria $>1,0 \mathrm{~g} / 24 \mathrm{~h}$ e niveis de creatinina elevados. ${ }^{7}$

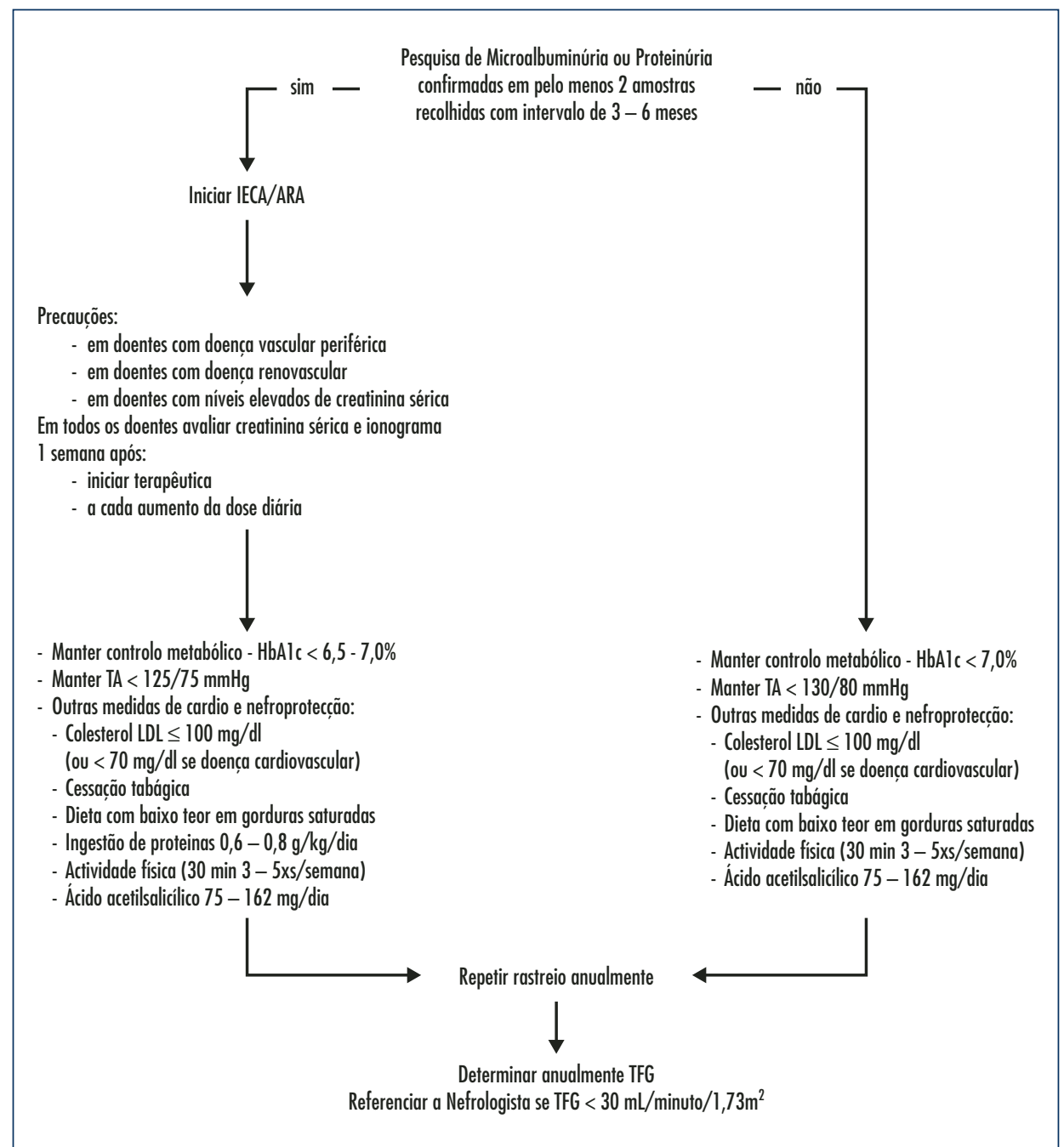

Figura 2. Algoritmo de Prevenção e Terapêutica da Nefropatia Diabética. 


\section{IECA's}

Estes fármacos reduzem a vasoconstrição ao nivel das arteríolas eferentes renais e a sua utilidade no tratamento de doentes com nefropatia diabética prende-se com o seu efeito nefroprotector, independente da redução da tensão arterial. ${ }^{69,70,84}$

Estudos demonstram que os IECA's têm um impacto mais eficaz na redução da proteinúria que outros agentes antihipertensores (cerca de 40\% em comparação com $17 \%$ das outras drogas). ${ }^{85}$

Em doentes diabéticos do tipo 1, estes fármacos mostraram ser eficazes na redução da progressão da micro para macroalbuminúria, bem como na regressão da micro para normoalbuminúria, comparativamente com o placebo. ${ }^{86}$ Os agentes utilizados neste estudo foram o captopril, enalapril, lisinopril, perindopril e ramipril.

Um outro estudo, no mesmo grupo de doentes, concluiu que a administração de captopril reduz significativamente o risco de IRC terminal, transplante renal ou morte, num período de três anos, comparativamente com o placebo. ${ }^{87} \mathrm{Cer}$ ca de $1,5 \%$ dos participantes sob terapêutica com o IECA apresentaram, como efeito secundário, hipercaliémia.

Na diabetes tipo 2, comparativamente com o placebo, os IECA's mostraram ser eficazes na redução da progressão de micro para macroalbuminúria, num período de três anos. ${ }^{73}$

A administração de ramipril na dose de $10 \mathrm{mg} /$ dia mostrou-se eficaz na redução da progressão para proteinúria persistente e do risco de morte por eventos cardiovasculares (enfarte agudo do miocárdio, acidente vascular cerebral) em cerca de $24 \%$ a 4,5 anos. ${ }^{73}$ A tosse foi o principal efeito adverso apontado neste estudo.

Ensaios clínicos com enalapril na dose de $10 \mathrm{mg} /$ dia também se mostraram eficazes na redução do risco de progressão da nefropatia diabética ao fim de um período de cinco anos. ${ }^{88}$

Não foram encontrados estudos sobre o efeito dos IECA's na progressão da nefropatia para IRC terminal e transplante renal.

A subida dos niveis de creatinina de cerca de 30-35\%, com estabilização ao fim de dois meses, pode ser esperada em doentes com proteinúria e valores de creatinina $>1,4 \mathrm{mg} / \mathrm{dl}$ que iniciam terapêutica com IECA's. ${ }^{89} \mathrm{O}$ aumento da creatinina sérica está associado aos efeitos nefroprotectores destes fármacos a longo prazo pelo que não significa que tenham de ser descontinuados. ${ }^{89}$ Uma subida > 50\% deve fazer suspeitar de estenose da artéria renal e deve ser investigada. A hipercaliémia também está descrita como efeito secundário da terapêutica com IECA's. ${ }^{88,90}$

\section{ARA's}

Não foram encontrados estudos comparativos dos efeitos dos ARA's versus placebo em doentes diabéticos do tipo 1, possivelmente por questões éticas, dado já terem sido provados os benefícios da terapêutica com IECA's em doentes deste grupo de risco e em virtude das semelhanças entre os dois grupos de fármacos.

Em doentes diabéticos tipo 2 com hipertensão e microalbuminúria, o ibersartan, na dose de 300 mg/dia, reduziu em 70\% a progressão para macroalbuminúria, quando administrado durante um período de dois anos, comparativamente com o placebo. ${ }^{91} \mathrm{O}$ ibersartan na dose de 150 mg/dia não provocou reduções significativas. ${ }^{91} \mathrm{O}$ efeito nefroprotector deste fármaco poderá estar relacionado com a diminuição dos biomarcadores inflamatórios responsáveis pela lesão endotelial. ${ }^{92}$

Comparativamente com os IECA's, ainda neste grupo de doentes, não se encontraram diferenças significativas na redução do declínio da TFG ou mortalidade por enfarte do miocárdio, acidente vascular cerebral ou insuficiên- 
cia cardíaca entre a administração de telmisartan $80 \mathrm{mg}$ e enalapril $20 \mathrm{mg}$, num período de cinco anos. ${ }^{93}$

Relativamente a doentes diabéticos tipo 2 com macroalbuminúria, um estudo comparativo, losartan versus placebo, concluiu que o primeiro reduz significativamente a progressão da nefropatia diabética para IRC terminal, num período de 3,4 anos, não apresentando, no entanto, diferenças relativamente à mortalidade cardiovascular. ${ }^{94}$ Neste estudo, tanto o losartan como o placebo foram administrados em conjunto com outros antihipertensores (bloqueadores dos canais de cálcio, diuréticos, bloqueadores $\alpha$ e $\beta$ ).

Um outro estudo, que comparou ibersartan com placebo, não encontrou diferenças significativas na redução da progressão da proteinúria para IRC terminal ou na mortalidade cardiovascular, tendo notado apenas uma redução na incidência de insuficiência cardíaca congestiva em doentes medicados com ibersartan. ${ }^{95}$

Os ARA's são a melhor alternativa aos IECA's quando existe intolerância aos últimos (tosse) e são os fármacos preferidos em doentes diabéticos tipo 2 com hipertrofia ventricular esquerda. ${ }^{96}$

A combinação de um ARA (candesar$\tan 16 \mathrm{mg} /$ dia) e um IECA (lisinopril 20 $\mathrm{mg} /$ dia) mostrou ter efeito sinérgico, tanto na redução da tensão arterial como na diminuição da excreção de albumina urinária em doentes diabéticos tipo $2 .{ }^{96}$

\section{Blogueadores dos Canais de cálcio}

Os resultados dos estudos sugerem que os efeitos nefroprotectores dos bloqueadores dos canais de cálcio não-dihidropiridinas (verapamil e diltiazem) são superiores aos explicados apenas pela descida dos valores de tensão arterial. ${ }^{97}$

Dentro da classe das dihidropiridinas, a nifedipina, comparativamente com o lisinopril, mostrou ter um efeito menos potente sobre a diminuição da progressão da doença renal em doen- tes com DM tipo $2 .{ }^{98}$ Ainda no mesmo grupo farmacológico, a nisoldipina parece ter efeito equivalente ao lisinopril na progressão da nefropatia diabética. ${ }^{99}$

\section{BLOgUEADORES $\beta$}

O estudo UKPDS 39 concluiu que, relativamente à progressão da doença renal, não havia diferenças significativas entre doentes medicados com atenolol e captopril. ${ }^{100}$ No entanto, uma maior percentagem de doentes sob terapêutica com atenolol foi obrigada a descontinuar devido a efeitos adversos do fármaco.

\section{Controlo da Glicemia}

A terapêutica intensiva com insulina para controlo da glicose, de forma a atingir niveis de $\mathrm{HbAlc}<7,0 \%$, foi mais eficaz na redução da progressão da nefropatia diabética em doentes diabéticos tipo 1 com micro e normoalbuminúria que o tratamento convencional. ${ }^{101}$ Nos dois grupos de participantes não houve diferença quanto à ocorrência de hipoglicemia, mas verificou-se maior incidência de cetoacidose diabética em doentes tratados com insulina em infusão. ${ }^{101}$

A escolha de antidiabéticos orais no tratamento da diabetes tipo 2 em doentes com patologia renal deve ser extremamente criteriosa.

A metformina não deve ser utilizada quando perante niveis de creatinina sérica $>1,5 \mathrm{mg} / \mathrm{dl}$ em doentes diabéticos do sexo masculino ou $>1,4 \mathrm{mg} / \mathrm{dl} \mathrm{em}$ doentes do sexo feminino, devido ao risco de acidose láctica. ${ }^{102}$ As sulfunilureias, à excepção da glimepirida, não devem ser utilizadas em doentes com compromisso da função renal, já que a sua excreção se faz através do rim. ${ }^{103} \mathrm{~A}$ nateglinida tem uma via de eliminação independente do rim pelo que pode ser uma alternativa segura em diabéticos tipo 2 com nefropatia. ${ }^{103}$ Do mesmo modo, a rosiglitazona demonstrou ser segura no tratamento da diabetes em doentes com compromisso renal, con- 
tribuindo para a diminuição da excreção renal de albumina, podendo inclusivamente ter um efeito preventivo da evolução da nefropatia diabética. ${ }^{104}$

Um estudo realizado no Japão em doentes diabéticos tipo 2, durante um período de seis anos, concluiu que a administração de insulina em múltiplas injecções, com o objectivo de atingir uma HbAlc de 7,1\%, reduz o risco de progressão da nefropatia em $70 \% .{ }^{105}$ Este estudo é indicativo de que grande parte dos doentes diabéticos tipo 2 com nefropatia deverão ser tratados com insulina e não com terapêutica antidiabética oral, o que se justifica perante o baixo nível de insulina endógena nestes doentes associado à longa evolução da diabetes.

Não foram encontrados estudos relativos aos efeitos do controlo da glicemia na progressão da nefropatia diabética para IRC terminal em doentes com diabetes tipo 2.

\section{Restrição Proteica}

Comparativamente com a dieta normal, uma dieta com baixo teor proteico $(0,5-$ $-0,85$ gramas de proteína $/ \mathrm{kg} /$ dia) durante um período de 4 anos mostrou ser eficaz na redução da evolução de micro para macroalbuminúria e diminuição da TFG em doentes diabéticos do tipo 1 com idades compreendidas entre os 18 e os 60 anos. ${ }^{38}$

Não foram encontradas evidências de que a restrição proteica da dieta tenha efeitos benéficos na redução da progressão da nefropatia diabética em doentes com diabetes tipo 2 .

\section{Perfil Lipídico}

Orientações internacionais recomendam valores de $\mathrm{LDL}<100 \mathrm{mg} / \mathrm{dl}$ nos doentes diabéticos, em geral, e $<70 \mathrm{mg} /$ /dl em diabéticos com patologia cardiovascular concomitante. ${ }^{106,107}$

Existem algumas evidências de que a redução dos níveis de LDL com o auxílio de estatinas possa preservar a função renal e reduzir a proteinúria. ${ }^{107}$ No entanto, a importância destes fármacos prende-se fundamentalmente com a redução do risco de morbilidade e mortalidade cardiovasculares neste grupo de doentes. ${ }^{78}$

\section{Anemia}

A anemia pode ocorrer em doentes diabéticos com nefropatia e é considerada um factor de risco na progressão da lesão renal. ${ }^{108}$ Está relacionada com o défice de eritropoietina e a terapêutica de substituição é recomendada quando perante valores de hemoglobina $<11 \mathrm{mg} / \mathrm{dl}$, de forma a atingir valores de $12-13 \mathrm{mg} / \mathrm{dl}$. A elevação da tensão arterial pode surgir como efeito secundário desta terapêutica. ${ }^{108}$

\section{Intervenção Multifactorial}

O tratamento multifactorial de doentes diabéticos tipo 2 com microalbuminúria mostrou ser eficaz na diminuição da progressão da doença renal mas também na redução da morbilidade e mortalidade cardiovasculares. ${ }^{109}$

A intervenção consistiu no controlo rigoroso da tensão arterial $<130 / 80$ $\mathrm{mmHg}$ ), glicemia ( $\mathrm{HbAlc}<6,5 \%$ ) e perfil lipídico (colesterol total $<175 \mathrm{mg} / \mathrm{dl}$ e triglicéridos < $150 \mathrm{mg} / \mathrm{dl}$ ), prescrição de um IECA (captopril 50 mg 2xs/dia) ou um ARA (losartan $50 \mathrm{mg} 2 \mathrm{xs} / \mathrm{dia}$ ), independentemente da terapêutica antihipertensora, e antiagregação plaquetária (AAS $150 \mathrm{mg} /$ dia) a todos os doentes, dieta com baixo teor de gorduras saturadas, exercício físico moderado (30 minutos, 3-5xs/semana) e um programa de cessação tabágica. As reduções no risco de nefropatia, retinopatia e neuropatia ao fim de 4 anos de intervenção mantêm-se até 8 anos. A redução do risco de eventos cardiovasculares e microvasculares foi de cerca de 50\%. ${ }^{109}$

\section{CONCLUSÃO}

A prevenção e o tratamento da nefropa- 
tia diabética baseiam-se numa intervenção multifactorial, que envolve o controlo apertado dos vários factores de risco (HTA, hiperglicemia, dislipidemia, tabagismo, nefrotoxinas), a utilização de agentes nefroprotectores (IECA's e/ou ARA's) e a modificação de estilos de vida (cessação tabágica, dieta, exercício físico), que não só contribuem para a diminuição da progressão da lesão renal como também modulam o risco de morbilidade e mortalidade cardiovasculares.

No futuro é possivel que surjam terapêuticas eficazes na reversão da nefropatia diabética; no entanto, neste momento, o diagnóstico precoce da diabetes e pré-diabetes e o início de terapêutica agressiva, destinada a prevenir o aparecimento de microalbuminúria, são a melhor aposta no combate às complicações renais da diabetes.

\section{REFERÊNCIAS BIBLIOGRÁFICAS}

1. Amos A, McCarty DJ, Zimmet P. The rising global burden of diabetes and its complications: estimates and projections to the year 2010. Diabet Med 1997; 14 Suppl 5: S1-85.

2. United States Renal Data System. USRDS 2006 Annual Data Report: Atlas of End-Stage Renal Disease in the United States. Disponivel em: URL: http://www.usrds.org/adr.htm [acedido em 12/04/2007].

3. Dinneen SF, Gerstein HC. The association of microalbuminuria and mortality in noninsulin-dependent diabetes mellitus: a systematic overview of the literature. Arch Intern Med 1997 Jul 14; 157 (13): 1413-8.

4. Mangrum A, Bakris GL. Predictors of renal and cardiovascular mortality in patients with non-insulin-dependent diabetes: a brief overview of microalbuminuria and insulin resistance. J Diabetes Complications 1997 NovDec; 11 (6): 352-7.

5. Morrish NJ, Wang SL, Stevens LK, Fuller $\mathrm{JH}$, Keen H. Mortality and causes of death in the WHO Multinational Study of Vascular Disease in Diabetes. Diabetologia 2001 Sep; 44 Suppl 2: S14-21.

6. De Zeeuw D, Remuzzi G, Parving HH, Keane WF, Zhang Z, Shahinfar S, et al. Albumi- nuria, a therapeutic target for cardiovascular protection in type 2 diabetic patients with nephropathy. Circulation 2004 Aug 24; 110 (8): 921-7.

7. Gross JL, de Azevedo MJ, Silveiro SP, Canani LH, Caramori ML, Zelmanovitz T. Diabetic nephropathy: diagnosis, prevention, and treatment. Diabetes Care 2005 Jan; 28 (1): 164-76.

8. Craig KJ, Donovan K, Munnery M, Owens DR, Williams JD, Phillips AO. Identification and management of diabetic nephropathy in the diabetes clinic. Diabetes Care 2003 Jun; 26 (6): 1806-11.

9. The Royal College of General Practitioners; University of Sheffield, Effective Clinical Practice Unit. Clinical Guidelines for Type 2 Diabetes. Diabetic renal disease: prevention and early management. Sheffield: University of Sheffield; 2002. Disponível em: URL: http://www.shef.ac.uk/guidelines [acedido em 05/04/2007].

10. Christensen PK, Rossing P, Nielsen FS, Parving HH. Natural course of kidney function in Type 2 diabetic patients with diabetic nephropathy. Diabet Med 1999 May; 16 (5): 388-94.

11. Christensen PK, Gall MA, Parving HH. Course of glomerular filtration rate in albuminuric type 2 diabetic patients with or without diabetic glomerulopathy. Diabetes Care 2000 Apr; 23 Suppl 2: B14-20.

12. Knudsen ST, Poulsen PL, Hansen KW, Ebbehøj E, Bek T, Mogensen CE. Pulse pressure and diurnal blood pressure variation: association with micro- and macrovascular complications in type 2 diabetes. Am J Hypertens 2002 Mar; 15 (3): 244-50.

13. Perassolo MS, Almeida JC, Prá RL, Mello VD, Maia AL, Moulin CC, et al. Fatty acid composition of serum lipid fractions in type 2 diabetic patients with microalbuminuria. Diabetes Care 2003 Mar; 26 (3): 613-8.

14. Beck MO, Silveiro SP, Friedman R, Clausell N, Gross JL. Asymptomatic coronary artery disease is associated with cardiac autonomic neuropathy and diabetic nephropathy in type 2 diabetic patients. Diabetes Care 1999 Oct; 22 (10): 1745-7.

15. Jenkins AJ, Lyons TJ, Zheng D, Otvos JD, Lackland DT, McGee D, et al. Lipoproteins in the DCCT/EDIC cohort: associations with diabetic nephropathy. Kidney Int 2003 Sep; 64 (3): 817-28.

16. Stehouwer CD, Gall MA, Twisk JW, Knudsen E, Emeis JJ, Parving HH. Increased urinary albumin excretion, endothelial 
dysfunction, and chronic low-grade inflammation in type 2 diabetes: progressive, interrelated, and independently associated with risk of death. DiabeteS 2002 Apr; 51 (4): 1157-65.

17. Gerstein HC, Mann JF, Yi Q, Zinman B, Dinneen SF, Hoogwerf B, et al. Albuminuria and risk of cardiovascular events, death, and heart failure in diabetic and nondiabetic individuals. JAMA 2001 Jul 25; 286 (4): 421-6.

18. Forsblom CM, Groop PH, Ekstrand A, Totterman KJ, Sane T, Saloranta C, et al. Predictors of progression from normoalbuminuria to microalbuminuria in NIDDM. Diabetes Care 1998 Nov; 21 (11): 1932-8.

19. Giorgino F, Laviola L, Cavallo Perin P, Solnica B, Fuller J, Chaturvedi N. Factors associated with progression to macroalbuminuria in microalbuminuric Type 1 diabetic patients: the EURODIAB Prospective Complications Study. Diabetologia 2004 Jun; 47 (6): 1020-8.

20. Murussi M, Baglio P, Gross JL, Silveiro SP. Risk factors for microalbuminuria and macroalbuminuria in type 2 diabetic patients: a 9-year follow-up study. Diabetes Care 2002 Jun; 25 (6): 1101-3.

21. Fioretto P, Steffes MW, Brown DM, Mauer SM. An overview of renal pathology in insulin-dependent diabetes mellitus in relationship to altered glomerular hemodynamics. Am J Kidney Dis 1992 Dec; 20 (6): 549-58.

22. Eknoyan G, Hostetter T, Bakris GL, Hebert L, Levey AS, Parving HH, et al. Proteinuria and other markers of chronic kidney disease: a position statement of the National Kidney Foundation (NKF. and the National Institute of Diabetes and Digestive and KidneyDiseases (NIDDK). Am J Kidney Dis 2003 Oct; 42 (4): 617-22.

23. Molitch ME, DeFronzo RA, Franz MJ, Keane WF, Mogensen CE, Parving HH, et al. Nephropathy in diabetes. Diabetes Care 2004 Jan; 27 Suppl 1: S79-83.

24. Powers A. Diabetes mellitus. In: Braunwald E, Fauci AS, Kasper DL, Hauser S, editors. Harrison's principles of internal medicine. $15^{\text {th }}$ ed. New York: McGraw-Hill; 2001. p 2116-27.

25. Harjutsalo V, Katoh S, Sarti C, Tajima $\mathrm{N}$, Tuomilehto J. Population-based assessment of familial clustering of diabetic nephropathy in type 1 diabetes. Diabetes 2004 Sep; 53 (9): 2449-54.

26. Pettitt DJ, Saad MF, Bennett PH, Nelson RG, Knowler WC. Familial predisposition to renal disease in two generations of Pima Indians with type 2 (non-insulin-dependent. dia- betes mellitus. Diabetologia 1990 Jul; 33 (7): 438-43.

27. Freedman BI, Tuttle AB, Spray BJ. Familial predisposition to nephropathy in African-Americans with non-insulin-dependent diabetes mellitus. Am J Kidney Dis 1995 May; 25 (5): 710-3.

28. Canani LH, Gerchman F, Gross JL. Familial clustering of diabetic nephropathy in Brazilian type 2 diabetic patients. Diabetes 1999 Apr; 48 (4): 909-13.

29. Gross JL, Stein AC, Beck MO, Fuchs SC, Silveiro SP, de-Azevedo MJ, Friedman R. Risk factors for development of proteinuria by type II (non-insulin dependent. diabetic patients. Braz J Med Biol Res 1993 Dec; 26 (12): 1269-78 .

30. De Cosmo S, Lamacchia O, Rauseo A, Viti R, Gesualdo L, Pilotti A, et al. Cigarette smoking is associated with low glomerular filtration rate in male patients with type 2 diabetes. Diabetes Care 2006 Nov; 29 (1 1): 2467-70.

31. Chaturvedi N, Fuller JH, Taskinen MR; EURODIAB PCS Group. Differing associations of lipid and lipoprotein disturbances with the macrovascular and microvascular complications of type 1 diabetes. Diabetes Care 2001 Dec; 24 (12): 2071-7.

32. Appel GB, Radhakrishnan J, Avram MM, DeFronzo RA, Escobar-Jiménez F, Campos MM, et al. Analysis of metabolic parameters as predictors of risk in the RENAAL study. Diabetes Care 2003 May; 26 (5): 1402-7.

33. Adler AI, Stratton IM, Neil HA, Yudkin JS, Matthews DR, Cull CA, et al. Association of systolic blood pressure with macrovascular and microvascular complications of type 2 diabetes (UKPDS 36): prospective observational study. BMJ 2000 Aug 12; 321 (7258): 412-9.

34. Nosadini R, Velussi M, Brocco E, Bruseghin M, Abaterusso C, Saller A, et al. Course of renal function in type 2 diabetic patients with abnormalities of albumin excretion rate. Diabetes 2000 Mar; 49 (3): 476-84.

35. Mokdad AH, Ford ES, Bowman BA, Nelson DE, Engelgau MM, Vinicor F, et al. Diabetes trends in the U.S.: 1990-1998. Diabetes Care 2000 Sep; 23 (9): 1278-83.

36. Hsu CY, Lin F, Vittinghoff E, Shlipak MG. Racial differences in the progression from chronic renal insufficiency to end-stage renal disease in the United States. J Am Soc Nephrol 2003 Nov; 14 (11): 2902-7.

37. Hallan SI, Coresh J, Astor BC, Asberg A, Powe NR, Romundstad S, et al. International comparison of the relationship of chronic kidney disease prevalence and ESRD risk. J Am 
Soc Nephrol 2006 Aug; 17 (8): 2275-84.

38. Hansen HP, Tauber-Lassen E, Jensen BR, Parving HH. Effect of dietary protein restriction on prognosis in patients with diabetic nephropathy. Kidney Int 2002 Jul; 62 (1): 220-8.

39. Remuzzi G, Schieppati A, Ruggenenti P. Clinical practice: nephropathy in patients with type 2 diabetes. N Engl J Med 2002 Apr 11;346 (15): 1145-51.

40. Chaturvedi N, Bandinelli S, Mangili R, Penno G, Rottiers RE, Fuller JH. Microalbuminuria in type 1 diabetes: rates, risk factors and glycemic threshold. Kidney Int 2001 Jul; 60 (1): 219-27.

41. Hovind P, Tarnow L, Rossing P, Jensen BR, Graae M, Torp I, et al. Predictors for the development of microalbuminuria and macroalbuminuria in patients with type 1 diabetes: inception cohort study. BMJ 2004 May 8; 328 (7448): 1105.

42. Adler AI, Stevens RJ, Manley SE, Bilous RW, Cull CA, Holman RR: UKPDS Group. Development and progression of nephropathy in type 2 diabetes: the United Kingdom Prospective Diabetes Study (UKPDS 64). Kidney Int 2003 Jan; 63 (1): 225-32.

43. Wong TY, Shankar A, Klein R, Klein BE. Retinal vessel diameters and the incidence of gross proteinuria and renal insufficiency in people with type 1 diabetes. Diabetes 2004 Jan; 53 (1): 179-84.

44. Klein R, Klein BE, Moss SE, Cruickshanks KJ, Brazy PC. The 10-year incidence of renal insufficiency in people with type 1 diabetes. Diabetes Care 1999 May; 22 (5): 743$-51$.

45. Valmadrid CT, Klein R, Moss SE, Klein $\mathrm{BE}$. The risk of cardiovascular disease mortality associated with microalbuminuria and gross proteinuria in persons with older-onset diabetes mellitus. Arch Intern Med 2000 Apr 24; 160 (8): 1093-100.

46. Hasslacher C, Ritz E, Wahl P, Michael C. Similar risks of nephropathy in patients with type I or type II diabetes mellitus. Nephrol Dial Transplant 1989; 4 (10): 859-63.

47. Cooper ME. Pathogenesis, prevention, and treatment of diabetic nephropathy. Lancet 1998 Jul 18; 352 (9123): 213-9.

48. Brito PL, Fioretto P, Drummond K, Kim Y, Steffes MW, Basgen JM, et al. Proximal tubular basement membrane width in insulin-dependent diabetes mellitus. Kidney Int 1998 Mar; 53 (3): 754-61.

49. Katz A, Caramori ML, Sisson-Ross S, Groppoli T, Basgen JM, Mauer M. An increase in the cell component of the cortical interstitium antedates interstitial fibrosis in type $1 \mathrm{di}$ abetic patients. Kidney Int 2002 Jun; 61 (6): 2058-66.

50. Fioretto P, Mauer M, Brocco E, Velussi M, Frigato F, Muollo B, et al. Patterns of renal injury in NIDDM patients with microalbuminuria. Diabetologia 1996 Dec; 39 (12): 1569-76.

51. Caramori ML, Kim Y, Huang C, Fish AJ, Rich SS, Miller ME, et al. Cellular basis of diabetic nephropathy: 1 . Study design and renal structural-functional relationships in patients with long-standing type 1 diabetes. Diabetes 2002 Feb; 51 (2): 506-13. Erratum in: Diabetes 2002 Apr; 51 (4): 1294.

52. Huang C, Kim Y, Caramori ML, Fish AJ, Rich SS, Miller ME, et al. Cellular basis of diabetic nephropathy: II. The transforming growth factor-beta system and diabetic nephropathy lesions in type 1 diabetes. Diabetes 2002 Dec; 51 (12): 3577-81.

53. White KE, Bilous RW. Type 2 diabetic patients with nephropathy show structuralfunctional relationships that are similar to type 1 disease. J Am Soc Nephrol 2000 Sep; 11 (9): 1667-73.

54. Bakker AJ. Detection of microalbuminuria: receiver operating characteristic curve analysis favors albumin-to-creatinine ratio over albumin concentration. Diabetes Care 1999 Feb; 22 (2): 307-13.

55. Bouhanick B, Berrut G, Chameau AM, Hallar M, Bled F, Chevet B, et al. Predictive value of testing random urine sample to detect microalbuminuria in diabetic subjects during outpatient visit. Diabete Metab 1992 Jan-Feb; 18 (1): 54-8.

56. Kouri TT, Viikari JS, Mattila KS, Irjala KM. Microalbuminuria: invalidity of simple concentration-based screening tests for early nephropathy due to urinary volumes of diabetic patients. Diabetes Care 1991 Jul; 14 (7): 591-3.

57. Webb DJ, Newman DJ, Chaturvedi N, Fuller JH. The use of the Micral-Test strip to identify the presence of microalbuminuria in people with insulin dependent diabetes mellitus (IDDM. participating in the EUCLID study. Diabetes Res Clin Pract 1996 Mar; 31 (1-3): 93$-102$.

58. Christensen PK, Larsen S, Horn T, Olsen S, Parving HH. Causes of albuminuria in patients with type 2 diabetes without diabetic retinopathy. Kidney Int 2000 Oct; 58 (4): 1719$-31$.

59. Christensen PK, Larsen S, Horn T, Olsen S, Parving HH. Renal function and struc- 
ture in albuminuric type 2 diabetic patients without retinopathy. Nephrol Dial Transplant 2001 Dec; 16 (12): 2337-47.

60. Gall MA, Hougaard P, Borch-Johnsen K, Parving HH. Risk factors for development of incipient and overt diabetic nephropathy in patients with non-insulin dependent diabetes mellitus: prospective, observational study. BMJ 1997 Mar 15; 314 (7083): 783-8.

61. Mauer M, Fioretto P, Woredekal Y, Friedman EA. Diabetic nephropathy. In: Schrier RW, editor. Diseases of the Kidney and Urinary Tract. 7th ed. Philadelphia, PA: Lippincott, Williams \& Wilkins; 2001. p. 2083-116.

62. Mogensen CE, Vestbo E, Poulsen PL, Christiansen C, Damsgaard EM, Eiskjaer H, et al. Microalbuminuria and potential confounders: a review and some observations on variability of urinary albumin excretion. Diabetes Care 1995 Apr; 18 (4): 572-81.

63. Comper WD, Jerums G, Osicka TM. Deficiency in the detection of microalbuminuria by urinary dipstick in diabetic patients. Diabetes Care 2003 Nov; 26 (11): 3195-6.

64. Levey AS, Coresh J, Balk E, Kausz AT, Levin A, Steffes MW, et al. National Kidney Foundation practice guidelines for chronic kidney disease: evaluation, classification, and stratification. Ann Intern Med 2003 Jul 15; 139 (2): 137-47. Erratum in: Ann Intern Med 2003 Oct 7; 139 (7): 605.

65. Gaspari F, Perico N, Remuzzi G. Measurement of glomerular filtration rate. Kidney Int Suppl 1997 Dec; 63: S151-4.

66. Caramori ML, Fioretto P, Mauer M. Low glomerular filtration rate in normoalbuminuric type 1 diabetic patients: an indicator of more advanced glomerular lesions. Diabetes 2003 Apr; 52 (4): 1036-40.

67. MacIsaac RJ, Tsalamandris C, Panagiotopoulos S, Smith TJ, McNeil KJ, Jerums G. Nonalbuminuric renal insufficiency in type 2 diabetes. Diabetes Care 2004 Jan; 27 (1): 195-200 .

68. UK Prospective Diabetes Study Group. Tight blood pressure control and risk of macrovascular and microvascular complications in type 2 diabetes: UKPDS 38. BMJ $1998 \mathrm{Sep}$ 12; 317 (7160): 703-13.

69. Mogensen CE. Microalbuminuria and hypertension with focus on type 1 and type 2 diabetes. J Intern Med 2003 Jul; 254 (1): 45-66 .

70. Viberti G, Wheeldon NM; MicroAlbuminuria Reduction With VALsartan (MARVAL. Study Investigators. Microalbuminuria reduction with valsartan in patients with type 2 dia- betes mellitus: a blood pressure-independent effect. Circulation 2002 Aug 6; 106 (6): 672-8.

71. Kvetny J, Gregersen G, Pedersen RS. Randomized placebo-controlled trial of perindopril in normotensive, normoalbuminuric patients with type 1 diabetes mellitus. QJM 2001 Feb; 94 (2): 89-94.

72. Lindholm LH, Ibsen H, Dahlof B, Devereux RB, Beevers G, de Faire U, et al.; LIFE Study Group. Cardiovascular morbidity and mortality in patients with diabetes in the Losartan Intervention For Endpoint reduction in hypertension study (LIFE): a randomised trial against atenolol. Lancet 2002 Mar 23; 359 (9311): 1004-10.

73. Heart Outcomes Prevention Evaluation Study Investigators. Effects of ramipril on cardiovascular and microvascular outcomes in people with diabetes mellitus: results of the HOPE study and MICRO-HOPE substudy. Heart Outcomes Prevention Evaluation Study Investigators. Lancet 2000 Jan 22; 355 (9200): 253-9. Erratum in: Lancet 2000 Sep 2; 356 (9232): 860.

74. National Heart, Lung, and Blood Institute. The Seventh Report of the Joint National Committee on Prevention, Detection, Evaluation, and Treatment of High Blood Pressure: the JNC 7 report. National Heart, Lung, and Blood Institute Joint National Committee on Prevention, Detection, Evaluation, and Treatment of High Blood Pressure. Disponivel em: URL: http://www.nhlbi.nih.gov/guidelines/hypertension/express.pdf [acedido em 21/04/2007].

75. Writing Team for the Diabetes Control and Complications Trial/Epidemiology of Diabetes Interventions and Complications Research Group. Sustained effect of intensive treatment of type 1 diabetes mellitus on development and progression of diabetic nephropathy: the Epidemiology of Diabetes Interventions and Complications (EDIC. study. JAMA 2003 Oct 22; 290 (16): 2159-67.

76. UK Prospective Diabetes Study Group. Intensive blood-glucose control with sulphonylureas or insulin compared with conventional treatment and risk of complications in patients with type 2 diabetes (UKPDS 33). Lancet 1998 Sep 12; 352 (9131): 837-53. Erratum in: Lancet 1999 Aug 14; 354 (9178): 602.

77. Tonolo G, Ciccarese M, Brizzi P, Puddu L, Secchi G, Calvia P, et al. Reduction of albumin excretion rate in normotensive microalbuminuric type 2 diabetic patients during longterm simvastatin treatment. Diabetes Care 1997 Dec; 20 (12): 1891-5. 
78. Wanner C, Drechsler C, Krane V. Lipid metabolism in chronic kidney disease: the role of statins in cardiovascular risk. J Ren Nutr 2007 Jan; 17 (1): 75-8.

79. Hovind P, Rossing P, Tarnow L, Parving HH. Smoking and progression of diabetic nephropathy in type 1 diabetes. Diabetes Care 2003 Mar; 26 (3): 911-6.

80. Huerta C, Castellsague J, Varas-Lorenzo C, García Rodríguez LA. Nonsteroidal antiinflammatory drugs and risk of ARF in the general population. Am J Kidney Dis. 2005 Mar; 45 (3): 531-9.

81. Hansen HP, Gaede PH, Jensen BR, Parving HH. Lack of impact of low-dose acetylsalicylic acid on kidney function in type 1 diabetic patients with microalbuminuria. Diabetes Care 2000 Dec; 23 (12): 1742-5.

82. Colwell JA. Aspirin therapy in diabetes. Diabetes Care 2004 Jan; 27 Suppl 1: S72-3.

83. Rihal CS, Textor SC, Grill DE, Berger PB, Ting HH, Best PJ, et al. Incidence and prognostic importance of acute renal failure after percutaneous coronary intervention. Circulation 2002 May 14; 105 (19): 2259-64.

84. Hovind P, Rossing P, Tarnow L, Smidt UM, Parving HH. Remission and regression in the nephropathy of type 1 diabetes when blood pressure is controlled aggressively. Kidney Int 2001 Jul; 60 (1): 277-83.

85. Gansevoort RT, Sluiter WJ, Hemmelder $\mathrm{MH}$, de Zeeuw D, de Jong PE. Antiproteinuric effect of blood-pressure-lowering agents: a meta-analysis of comparative trials. Nephrol Dial Transplant 1995 Nov; 10 (11): 1963-74.

86. ACE Inhibitors in Diabetic Nephropathy Trialist Group. Should all patients with type 1 diabetes mellitus and microalbuminuria receive angiotensin-converting enzyme inhibitors? A meta-analysis of individual patient data. Ann Intern Med 2001 Mar 6; 134 (5): 370-9.

87. Lewis EJ, Hunsicker LG, Bain RP, Rohde RD. The effect of angiotensin-convertingenzyme inhibition on diabetic nephropathy. The Collaborative Study Group. N Engl J Med 1993 Nov 11; 329 (20): 1456-62. Erratum in: N Engl J Med 1993 Jan 13; 330 (2): 152.

88. Ravid M, Savin H, Jutrin I, Bental T, Katz B, Lishner M. Long-term stabilizing effect of angiotensin-converting enzyme inhibition on plasma creatinine and on proteinuria in normotensive type II diabetic patients. Ann Intern Med 1993 Apr 15; 118 (8): 577-81.

89. Bakris GL, Weir MR. Angiotensin-converting enzyme inhibitor-associated elevations in serum creatinine: is this a cause for concern? Arch Intern Med 2000 Mar 13; 160 (5):685-93.
90. Bakris GL, Siomos M, Richardson D, Janssen I, Bolton WK, Hebert L, et al. ACE inhibition or angiotensin receptor blockade: impact on potassium in renal failure. VAL-K Study Group. Kidney Int 2000 Nov; 58 (5): 2084-92.

91. Irbesartan in Patients with Type 2 Diabetes and Microalbuminuria Study Group. The effect of irbesartan on the development of diabetic nephropathy in patients with type 2 diabetes. N Engl J Med 2001 Sep 20; 345 (12): 870-8.

92. Persson F, Rossing P, Hovind P, Stehouwer CD, Schalkwijk C, Tarnow L, Parving $\mathrm{HH}$. Irbesartan treatment reduces biomarkers of inflammatory activity in patients with type 2 diabetes and microalbuminuria: an IRMA 2 substudy. Diabetes 2006 Dec; 55 (12):3550-5.

93. Diabetics Exposed to Telmisartan and Enalapril Study Group. Angiotensin-receptor blockade versus converting-enzyme inhibition in type 2 diabetes and nephropathy. $\mathrm{N}$ Engl $\mathrm{J}$ Med 2004 Nov 4; 351 (19): 1952-61.

94. RENAAL Study Investigators. Effects of losartan on renal and cardiovascular outcomes in patients with type 2 diabetes and nephropathy. N Engl J Med 2001 Sep 20; 345 (12): 861-9.

95. Lewis EJ, Hunsicker LG, Clarke WR, Berl T, Pohl MA, Lewis JB, et al. Renoprotective effect of the angiotensin-receptor antagonist irbesartan in patients with nephropathy due to type 2 diabetes. N Engl J Med 2001 Sep 20; 345 (12): 851-60.

96. Mogensen CE, Neldam S, Tikkanen I, Oren S, Viskoper R, Watts RW, et al. Randomised controlled trial of dual blockade of reninangiotensin system in patients with hypertension, microalbuminuria, and non-insulin dependent diabetes: the candesartan and lisinopril microalbuminuria (CALM. study. BMJ 2000 Dec 9; 321 (7274): 1440-4.

97. Maki DD, Ma JZ, Louis TA, Kasiske BL. Long-term effects of antihypertensive agents on proteinuria and renal function. Arch Intern Med 1995 May 22; 155 (10): 1073-80.

98. Crepaldi G, Carta Q, Deferrari G, Mangili R, Navalesi R, Santeusanio F, et al. Effects of lisinopril and nifedipine on the progression to overt albuminuria in IDDM patients with incipient nephropathy and normal blood pressure. The Italian Microalbuminuria Study Group in IDDM. Diabetes Care 1998 Jan; 21 (1): 104-10 .

99. Tarnow L, Rossing P, Jensen C, Hansen BV, Parving HH. Long-term renoprotective effect of nisoldipine and lisinopril in type 1 diabetic patients with diabetic nephropathy. Dia- 


\section{DOSSIER}

Complicações da Diabetes

betes Care 2000 Dec; 23 (12): 1725-30.

100. UK Prospective Diabetes Study Group. Efficacy of atenolol and captopril in reducing risk of macrovascular and microvascular complications in type 2 diabetes: UKPDS 39. BMJ 1998 Sep 12; 317 (7160): 713-20.

101. The Diabetes Control and Complications Trial/Epidemiology of Diabetes Interventions and Complications Research Group. Retinopathy and nephropathy in patients with type 1 diabetes four years after a trial of intensive therapy. N Engl J Med 2000 Feb 10; 342 (6): 381-9. Erratum in: N Engl J Med 2000 May 4; 342 (18): 1276.

102. Bailey CJ, Turner RC. Metformin. N Engl J Med 1996 Feb 29; 334 (9): 574-9.

103. Krentz AJ, Bailey CJ. Oral antidiabetic agents: current role in type 2 diabetes mellitus. Drugs 2005; 65 (3): 385-411.

104. Bakris G, Viberti G, Weston WM, Heise M, Porter LE, Freed MI. Rosiglitazone reduces urinary albumin excretion in type II diabetes. J Hum Hypertens 2003 Jan; 17 (1): 7-12.

105. Shichiri M, Kishikawa H, Ohkubo Y, Wake N. Long-term results of the Kumamoto Study on optimal diabetes control in type 2 diabetic patients. Diabetes Care 2000 Apr; 23 Suppl 2: B21-9.

106. National Heart, Lung, and Blood Ins- titute. Detection, evaluation and treatment of high blood cholesterol in adults (Adult Treatment Panel III): Final Report. Disponivel em: URL: http://www.nhlbi.nih.gov/guidelines/ cholesterol/atp3full.pdf [acedido em 21/04/ /2007]

107. Collins R, Armitage J, Parish S, Sleigh P, Peto R; Heart Protection Study Collaborative Group. MRC/BHF Heart Protection Study of cholesterol-lowering with simvastatin in 5963 people with diabetes: a randomised placebo-controlled trial. Lancet 2003 Jun 14; 361 (9374): 2005-16.

108. Thomas S, Rampersad M. Anaemia in diabetes. Acta Diabetol 2004 Mar; 41 Suppl 1: S13-7.

109. Gaede P, Vedel P, Larsen N, Jensen GV, Parving HH, Pedersen O. Multifactorial intervention and cardiovascular disease in patients with type 2 diabetes. N Engl J Med 2003 Jan 30; 348 (5): 383-93.

\section{Endereço para correspondência}

Cláudia Freitas Antão

Rua da Penha de França, 120 - 6ํㅡ D

1170-307 Lisboa

Telefone: 917065821

E-mail: claudia_antao@hotmail.com

\section{ABSTRACT}

Introduction: Diabetic nephropathy affects 10 to $40 \%$ of diabetic patients and is the leading cause of chronic renal disease in patients starting renal dialysis. With the increase in the prevalence of diabetes mellitus worldwide, along with the increase in the survival rate of diabetic patients, increases in the prevalence of diabetes complications will undoubtedly follow. Nephropathy has been shown to be an independent risk factor for early death due to cardiovascular diseases in diabetic patients, making it all the more urgent to adopt measures in clinical practice that aid in the early diagnosis and prevention of diabetic renal disease.

Objective: The aim of this article is to discuss the concepts, risk factors, screening methods and therapeutic strategies that promote reno- and cardioprotection in diabetic nephropathy Methods: We searched Medline, Pubmed Central, TRIP Database, Bandolier, National Guideline Clearinghouse and Index RMP online for systematic reviews and randomised controlled trials. In this review we included 104 articles from all the articles identified.

Conclusion: Diabetic nephropathy is characterized by persistent albuminuria, hypertension and a decline in renal function. Prevention and treatment consist of tight glucose control and blood pressure control. Early angiotensin blockade, even before the onset of microalbuminuria, is recommended to prevent the progression of renal disease and related cardiovascular morbidity and mortality. Other measures such as lipid control, diet, exercise, weight loss and smoking cessation may also inhibit the progression of diabetic nephropathy.

Key-Words: Diabetes Mellitus; Diabetes Mellitus complications; Nephropathy; Microlbuminuria; Macroalbuminuria; Cardiovascular risk. 